\title{
A combined high and low spatial resolution approach for mapping snow covered area in the Atlas mountains
}

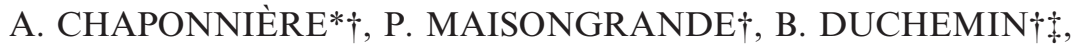 \\ L. HANICH\&, G. BOULET $\dagger+$, R. ESCADAFAL $\uparrow$ and S. ELOUADDAT \\ $\dagger$ Centre d'Etudes Spatiales de la Biosphère, Toulouse, France \\ Faculté des Sciences Semilalia, Université Caddi Ayyad, Marrakech, Morocco \\ $\S$ Faculté des Sciences et Techniques Semilalia, Université Caddi Ayyad, Marrakech, \\ Morocco \\ - Agence de Bassin Hydraulique du Tensift, Marrakech, Morocco
}

(Received 21 June 2004; in final form 11 January 2005)

\begin{abstract}
Dynamics of snow in semi-arid mountains are poorly investigated despite the fact that snow may represent an important source of water for downstream populations especially in the spring and early summer. Data acquired by space-borne optical sensors (i.e. reflectance and derived snow indices) may be suitable for spatial and temporal monitoring of snow cover. However, due to prevailing terrain and climatic conditions, the use of satellite sensor data to monitor snow dynamics is not trivial over such regions. Snowfall as well as precipitation are characterized by strong space-time variability. Indeed snow can fall and melt within one week. Under such conditions, appropriate monitoring of snow dynamics requires space instruments that provide data with high spatial and high temporal resolutions. In this context we developed a new approach based on the combination of two types of instruments: low spatial and high temporal resolution (Système Probatoire de l'Observation de la Terre (SPOT)VEGETATION) and high spatial and low temporal resolution (Landsat Thematic Mapper). This new approach improves the relationship between snow index and snow area. The method is validated against snow maps derived from classification of high spatial resolution data on the Atlas range, in Morocco. It is then applied to a one-year series of SPOT-4 VEGETATION images allowing to derive a temporal snow cover profile at $1 \mathrm{~km}$ spatial resolution over the entire Atlas. The yearly snow profile obtained is of great interest for hydrological modelling.
\end{abstract}

\section{Introduction}

Sustainable management of water resource is of primary concern in south Morocco, where drought and water shortages are rather the rule than the exception. A first step towards sustainable management of such scarce resource is an accurate assessment of the water balance dynamics at the basin scale. The Atlas is the most important mountain range in Morocco: it is around $800 \mathrm{~km}$ long and $70 \mathrm{~km}$ wide and made of three units - the anti, high and middle Atlas - located in the centre and in the north-east of the country. These mountains represent an important water

*Corresponding author. Email: anne.chaponniere@cesbio.cnes.fr. Tel: 0033-561 556 670; Fax: 0033-561 558500 
storage because of the orographic effect, i.e. increasing rainfall with elevation. Given the high elevations (the highest point culminates at $4200 \mathrm{~m}$ above sea level at the Jbel Toubkal, the highest summit of North Africa), precipitation is liquid as well as solid in this area. The regional hydrological organization 'Agence de Bassin Hydraulique $\mathrm{du}$ Haouz-Tensift' is in charge of the monitoring of the high-atlasic river discharge. Because of management costs and difficult access, its observation network is located in valleys, thus no observations at high elevation are made. Therefore, the snow dynamics is not routinely monitored although snowmelt obviously contributes to runoff during spring.

The estimation of spatially-distributed information on snow-covered areas (SCA) is a critical issue for hydrological modelling (Rosenthal 1993, Metsämäki et al. 2002). Indeed, SCA can be interpreted as an indicator of snow water equivalent. In this sense, it represents the snow-water storage (Blöschl 1999). Optical space-borne sensors are useful for monitoring SCA at regional scale thanks to the very specific optical properties of snow (high visible and low mid-infrared reflectance properties). This triggers a growing interest in satellite estimates of SCA with different types of sensors (Système Probatoire de l'Observation de la Terre VEGETATION (SPOTVGT), National Oceanic and Atmospheric Administration Advanced Very High Resolution Radiometer (NOAA-AVHRR), Landsat Thematic Mapper (TM) in Dozier 1989, Robinson 1993, Rosenthal and Dozier 1996, Simpson et al. 1998, Fortin et al. 2000, Akyürek and Sorman 2002).

The high latitudes of the Northern Hemisphere are continuously monitored for SCA since the late 1960s (Robinson et al. 1993). Snow can cover up to $40 \%$ of the land surface during the Northern Hemisphere winter (Hall et al. 1995). At high latitudes snow cover remains fairly constant for a long period of time. During this period, significant variations in snow depth or/and density lead to very important water release fluctuations. Thorough investigations of snow depth and density are thus conducted to obtain estimations of the water equivalent. Snow depth and density can be retrieved from remote sensing data via methodologies based on microwave radiometers (Hallikainen and Jolma 1992).

At low latitudes, the snow cover is non-permanent and experiences rapid variations during winter. These variations almost directly reflect the fluctuations of the water storage. Therefore, the monitoring of SCA represents a significant step towards the assessment of the contribution of snowmelt to runoff and thus towards accurate water balance modelling of the watershed. High frequency remotely sensed images, such as the ones provided at low $(1 \mathrm{~km})$ spatial resolution by large field-ofview sensors, are valuable datasets for this type of monitoring. Generally, methods for retrieving SCA are based on a snow index derived from low resolution data and converted into coverage. The conversion assumes a linear relationship, the index-toarea relation, between two reference values. These reference values are: the snow index corresponding to $100 \%$ snow cover ' $\mathrm{SI}_{100}$ ' and the one corresponding to $0 \%$ snow cover, 'SI,'.

According to prevailing terrain and climatic conditions in atlasic mountains, snow as well as precipitation are characterized by a strong space-time variability: snow can fall and melt within one week. In these conditions, appropriate monitoring of snow dynamics requires space instruments that provide data with high spatial and temporal resolutions. Such instruments are not currently available - at least for civilian applications. Therefore, our objective here is to develop an optimal method to extract accurate SCA maps from low spatial resolution data. The methods 
investigated are of two types: reference value methods (described previously) and 'improved' methods which combine high and low spatial resolution data. High spatial resolution data, such as those provided by Landsat TM (30 m resolution), are very accurate. They are thus more suited for snow cover analysis in mountainous zones compared to low spatial resolution data. Unfortunately, in the best case they are only available at a 16-day time-interval, which is not frequent enough for snow cover monitoring. However, low spatial resolution data, such as SPOT-VGT images ( $1 \mathrm{~km}$ resolution), are available with a daily frequency.

By combining the two types of images, we attempt to improve the quality of the spatial information available at low resolution while maintaining the daily availability. The combination of high and low spatial resolution data has previously been explored (Maselli et al. 1998, Fortin et al. 2000, Salomonson and Appel, 2004) and showed good results. The very specific context on which the methods are tested in this study - snow cover on mountainous semi-arid terrain - is challenging.

This paper is organized as follows: the next section presents the site on which this study was conducted along with the material used - the satellite and ground data as well as the digital elevation model. Then the methodology section describes the different SCA mapping methods that are implemented and developed. The results obtained by each method are compared and discussed in a third section. Finally, after the validation of a single method, its application to SPOT-VGT time series images is illustrated in the last section.

\section{Material}

In this section, the region of interest (High Atlas) is presented, along with all the data used in this study. We work with two types of images: a time series of low spatial resolution SPOT-VGT data and two high spatial resolution Landsat TM images. We use also ground data and a digital elevation model.

\subsection{Site description}

The study takes place in the Tensift watershed in central Morocco; the city of Marrakech lies in the centre of this region (figure 1). This watershed covers $20450 \mathrm{~km}^{2}$ and is composed of three parts: the northern 'Jbilet' hills, the 'Haouz' plain and the northern side of the high Atlas mountain range. The Tensift wadi flows sporadically from east to west and is supplied mainly from the basin's south bank: the Atlas north hillsides. The Atlas range is indeed the region's water tower, supplying several big irrigated areas in the plain (Cruette 1976, ORSTOM 1976).

The high Atlas is mainly composed of metamorphic and eruptive formations, which are impervious. Some pervious zones are still present, due to calcareous and marly sandstone formations or local weathering of the impervious formations. These pervious zones are probably responsible for additional delay in runoff. The Atlas's relief is very sharp with steep slopes. Land cover consists in sparse trees below $2000 \mathrm{~m}$ above sea level (coniferous and juniper), and bare rocks above. Soils are almost non-existent on the slopes because of high erosion. In the very narrow valleys, where the eroded sediments accumulate, deep soils are present on which crops are grown. The mean annual precipitation in Marrakech (elevation $460 \mathrm{~m}$ ) is $225 \mathrm{~mm}$, it reaches around $400 \mathrm{~mm}$ at $1000 \mathrm{~m}$ and is estimated around $500-600 \mathrm{~mm}$ at $3000 \mathrm{~m}$ (1970-2000 period; ORSTOM 1976). Snow covers the Atlas range each year. It contributes to mountainous runoff in a significant part two to three months 


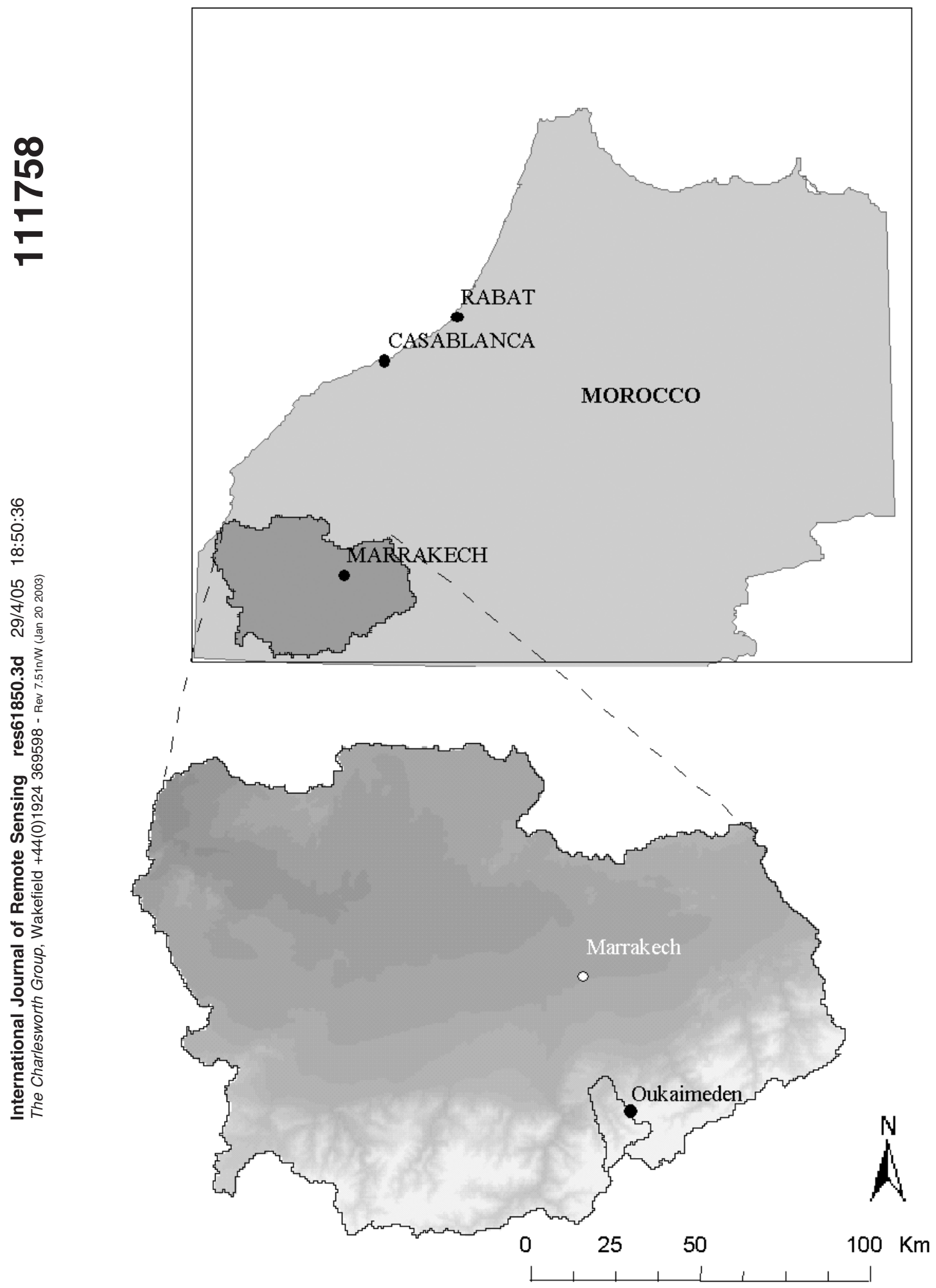


after the first snowfall events (De Solan et al. 2002, Chaponnière et al. 2003, Hanich et al. 2003). A typical Atlasic sub-watershed hydrological regime is presented in figure 2 . The monthly mean rainfall signal precedes the monthly mean runoff signal by two to three months in winter and spring seasons. This runoff delay is due to snow and deep infiltration in the bedrock's pervious zones.

\subsection{Satellite sensor data}

Since 1984, seven successive Landsat satellite missions have acquired images, at 16day time-intervals. When cloud-free, the images are suited for the detailed estimation of SCA. Indeed, the sensor's $30 \mathrm{~m}$ resolution is small compared to the scale of topographic relief in mountainous regions (Rosenthal and Dozier 1996). In addition, its spectral characteristics - four bands in the visible and near-infrared and two bands in the middle infrared - are adapted to snow detection. We acquired two Landsat TM cloud-free scenes over the Atlasic zone: on 8 February 2002 and on 3 February 2000; 8 February 2002 is our calibration date and 3 February 2000 our validation date.

The VEGETATION sensor, launched on the SPOT-4 platform in April 1998, acquires top of atmosphere radiances at $1 \mathrm{~km}$ resolution in four optical spectral bands: blue, red, near-infrared (NIR) and middle infrared (MIR). The use of an index based on a combination of different VEGETATION channels is well adapted to snow detection (Fortin et al. 2000). Among the different products, the first level VEGETATION P-data are recommended for this type of study (Maisongrande et al. 2004). Images with low viewing angles (important criterion as the region of interest presents a high relief) and without large clouds are selected from the online SPOT-VGT catalogue. We use two clear images (8 February 2002 and 3 February 2000) for the method calibration and validation against Landsat TM data. One time series of 35 images is also acquired during the winter 1998-99. Note that the SPOTVGT image of 3 February 2000 presents an acquisition problem for one cell of the charge-coupled device in the MIR channel. It generates a line with missing data, appearing with the background colour on the illustrations of figure 8 . This source of error is considered as negligible.

The SPOT-VGT images are acquired over Morocco between 10:50 and 11:00 GMT. The acquisition time of Landsat TM scenes was 10:56 GMT on 3 February 2000 and 10:53 GMT on 8 February 2002. For these two dates, SPOT-VGT and Landsat TM images are then quite comparable from their time of acquisition, preventing significant changes of the SCA. They only differ in resolution. Figure 3(a) presents the SPOT-VGT and figure $3(b)$ the Landsat TM images acquired over the Atlas on 8 February 2002. For each date, the high resolution Landsat TM image is degraded to $1 \mathrm{~km}$ resolution and superimposed to the SPOTVGT image.

\subsection{Ground data}

The Rehraya watershed is located south of the Tensift region and covers $228 \mathrm{~km}^{2}$ (see figure 1). Daily precipitation and runoff measurements are collected

Figure 1. The Tensift watershed, central Morocco, delineated on the digital elevation model; Marrakech city is located in the middle of the watershed, the Oukaïmeden ski resort is situated in the high Atlas on the eastern border of the Rehraya Atlasic head-watershed. 


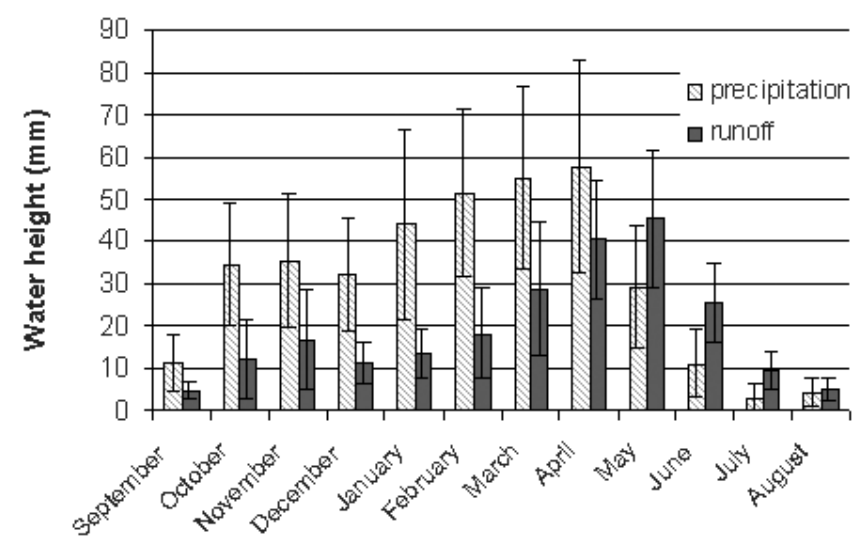

Figure 2. Thirty years (1970-2000) mean precipitation and runoff water-heights (mm) of the Rehraya head-watershed (see figure 1 for location).

(a)

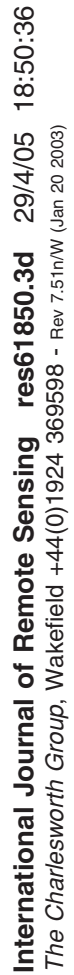

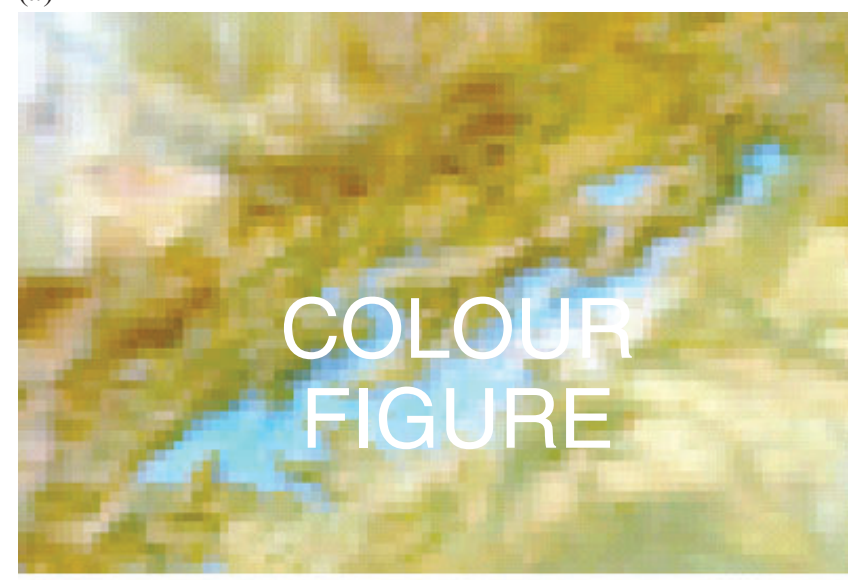

(b)

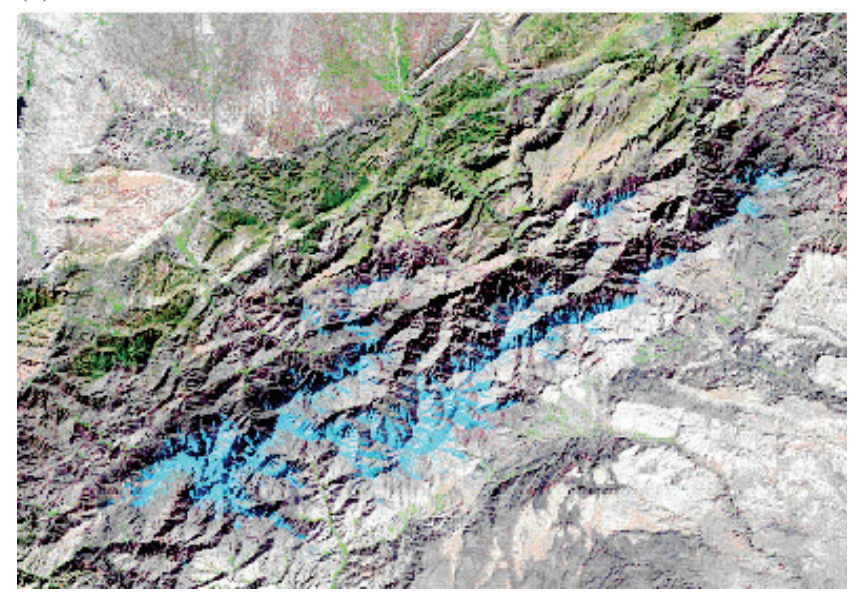

Figure 3. (a) Low (SPOT-VGT, $1 \mathrm{~km}$ resolution, daily time-step) and (b) high (Landsat TM, $30 \mathrm{~m}$ resolution, 16 day time-step) resolution image of the same scene over the high Atlas mountain range, on 8 February 2002. 
at its outlet by the 'Agence de Bassin Hydraulique du Haouz-Tensift'. These are used to illustrate the relation between SCA temporal profiles and the outlet hydrograph.

\subsection{Digital elevation model and derivatives}

Errors due to the effects of topography can be large because satellite data depict a flat surface and do not permit areal snow cover to be mapped on mountain slopes. Without the use of a digital elevation model (DEM), SCA can be greatly underestimated in mountainous areas (Hall et al. 1995). The Atlas range is a highly mountainous zone presenting very steep slopes. The acquisition of a good quality and high spatial resolution DEM is necessary for this study. The contour lines (50 m spaced) of 1:250000 maps covering our zone are digitized and interpolated, leading to a $100 \mathrm{~m}$ resolution DEM. From the DEM, two derivative data are produced: $100 \mathrm{~m}$ slope and aspect maps. The slope map is degraded to a kilometric resolution and used for correction. A simple correction is applied on our zone by dividing the 'plane' estimated SCA by the local slope cosine. The $100 \mathrm{~m}$ aspect map is used in the algorithm developed for the Landsat TM binary classification (see below).

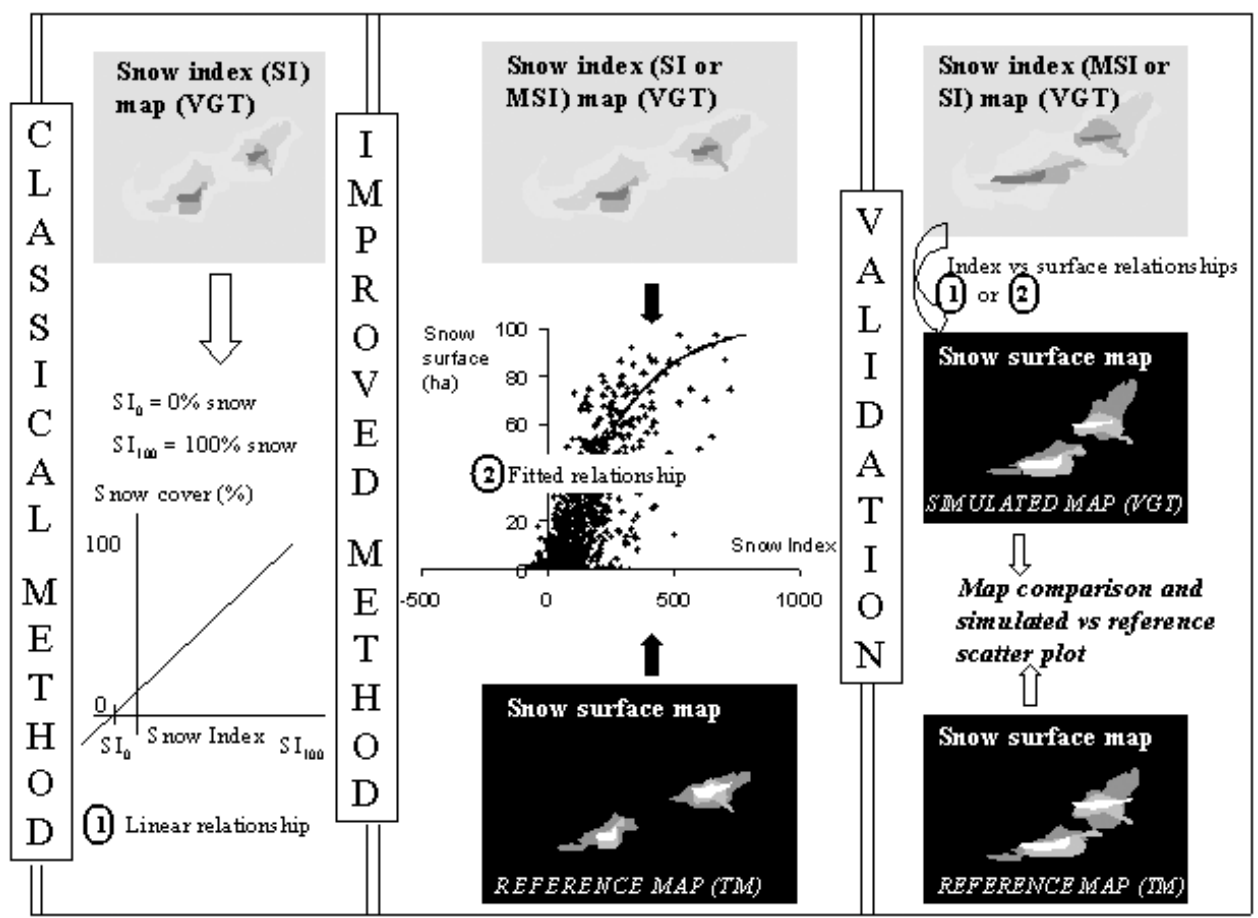

Figure 4. Illustration of the different methods developed and compared in this paper. The classical method (use of low resolution data only, linear index-to-area relationship based on reference values) and the improved method (combination of high and low resolution data to establish a nonlinear index-to-area relationship) are schematized. Validation of the different methods is performed by comparison to reference image derived from the high resolution data. 


\section{Methodology}

As described in figure 4, the methodology we develop consists of four steps.

1. Through the classification of high spatial resolution images (Landsat TM), ' $30 \mathrm{~m}$ reference snow images' are derived. These images are degraded to $1 \mathrm{~km}$ resolution leading to 'reference SCA maps'. These maps can be superimposed on low resolution data.

2. Snow index maps are calculated from SPOT-VGT images. Two snow indices are investigated: the snow index (SI) and the modified snow index (MSI).

3. Conversion of the snow index maps to $1 \mathrm{~km}$ SCA maps is achieved by applying different methods on SPOT-VGT data: 'classical' and 'improved' methods (see figure 4).

4. To evaluate these different methods, the simulated SCA maps are compared to the reference SCA map (see figure 4).

Several methods are tested depending on the way the 'index-to-area' relation is established and on the snow index used. There are four methods (table 1) divided into two groups: 'classical' and 'improved' methods. For the classical methods the index-to-area relation is established by setting reference values: a unique reference value for the whole image (unique reference value method (URVM), see table 1) and local reference values (local reference value method (LRVM), see table 1). These methods use the snow index 'SI'. For the improved methods, the index-to-area relation is established on numerous points. The points are derived from the combination of high and low resolution data. One method uses the SI, it is called the HR-LR_SI method (see table 1); and another the MSI, the HR-LR_MSI method (see table 1). The four steps of the methodology are detailed in the following sections.

\subsection{Reference snow covered areas (SCA) maps}

At high resolution, snow mapping has been widely studied. Rango and Itten (1976) investigated snow mapping using supervised and unsupervised computer classification techniques from Landsat Multispectral Scanner System (MSS) data. Dozier (1989) used apparent planetary reflectance from TM data. These techniques lead to a binary classification: pixels are classified as 'snow' or 'no snow'. Rosenthal (1993)

Table 1. The four different methods investigated in this paper regarding the snow indices and the index-to-area relations.

\begin{tabular}{lll}
\hline & \multicolumn{2}{c}{ Indices } \\
\cline { 2 - 3 } Index-to-area relations & \multicolumn{1}{c}{ Snow index (SI) } & \multicolumn{1}{c}{$\begin{array}{c}\text { Modified snow index } \\
\text { (MSI) }\end{array}$} \\
\hline $\begin{array}{l}\text { Reference values 'clas- Unique } \\
\text { sical methods' }\end{array}$ & $\begin{array}{l}\text { Unique reference values } \\
\text { method (URVM) } \\
\text { Local reference values method } \\
\text { (LRVM) }\end{array}$ \\
$\begin{array}{lll}\text { Spatial high and low resolution } \\
\text { (HR and LR) data superimposition } \\
\text { 'improved methods' }\end{array}$ & $\begin{array}{l}\text { HR-LR method with SI } \\
\text { (HR-LR_SI) }\end{array}$ & $\begin{array}{l}\text { HR-LR method with } \\
\text { MSI (HR-LR_MSI) }\end{array}$ \\
\hline
\end{tabular}


and Rosenthal and Dozier (1996) investigated spectral mixture analysis (or spectral end members) to get pixel percentage of SCA.

As in Dozier (1989), we focus on the blue band reflectance to discriminate snow. The classification algorithm we develop is close to the one developed by Baral and Guptal (1997) in the Gharwal Himalayas. We superimpose the products derived from the DEM to the TM images and set thresholds on blue reflectance. These thresholds depend on the pixel's aspect and elevation. This method allows to account for snow shadowed areas which represent an important area in these very steep zones. A well documented problem in snow classification is snow and cloud confusion (Hall et al. 1998, Simpson et al. 1998). Here, the scenes are clear, therefore snow distinction is easy. This is why we first focus on the reflectance in the blue band. Visual validations of the resulting high resolution binary classifications is possible on such a small snow-covered zone. The Landsat TM images are compared to the classifications practically pixel-by-pixel. These validations showing reliable results, we decide to keep this simple classification method.

The high resolution snow classification is then degraded at a kilometric resolution: SCA in hectares are calculated at each low resolution pixel. We obtain (figure 5) the 'reference' SCA maps. These reference SCA maps are used in two ways: to calibrate and to validate the different relationships between SCA and snow indices.

\subsection{Snow indices}

Low resolution images are converted into two snow indices: a classical snow index (SI; equation(1)) and the modified snow index (MSI; equation(3)). The MSI is developed to subtract the soil spectral contribution from the signal.

The discrimination of snow from other surface types is based upon the difference in the visible and MIR wavelengths. The first index we use, the SI (equation(1)), is specifically proposed for the VEGETATION sensor (Lissens et al. 2000). It was

(a)

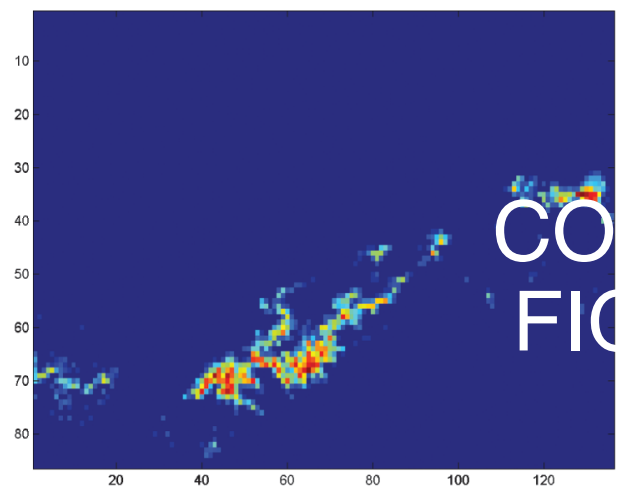

(b)

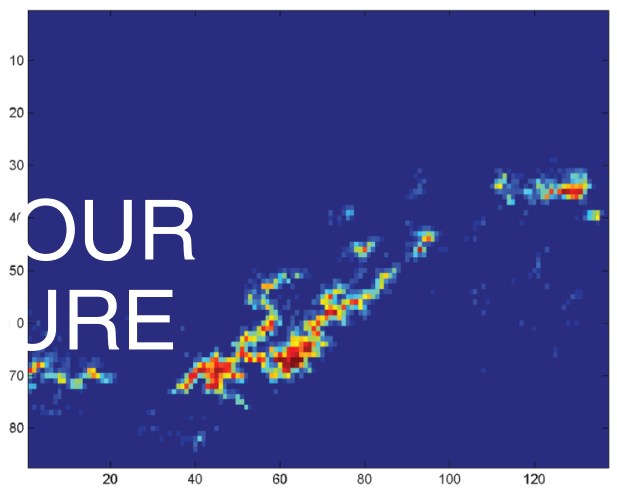

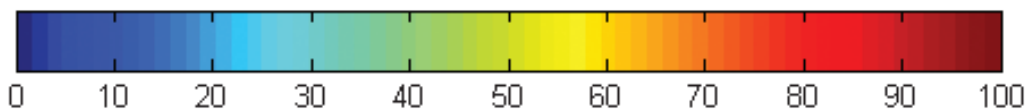

Figure 5. Reference snow surface maps for 8 February 2002 (a) and 3 February $2000(b)$, in hectares per pixel of $1 \mathrm{~km}^{2}$. These reference maps are obtained by degradation of the high resolution (Landsat TM, $30 \mathrm{~m}$ ) snow classifications. 
compared to the Normalized Difference Snow Index (equation (2)) for the Atlas in a previous work (De Solan et al. 2002, Hanich et al. 2003). Since the SI has shown better results in these studies, we decided to keep it. When expressed in digital counts (dc) the SI varies from the order of $-500 \mathrm{dc}$ to $1000 \mathrm{dc}$, the mean value being around $-200 \mathrm{dc}$ and the standard deviation around $100 \mathrm{dc}$ (depending on the day).

$$
\begin{aligned}
& \mathrm{SI}=\frac{B_{0}+B_{2}}{2}-\mathrm{MIR} \\
& \mathrm{NDSI}=\frac{B_{0}-\mathrm{MIR}}{B_{0}+\mathrm{MIR}}
\end{aligned}
$$

where $B_{0}$ is the blue top-of-atmosphere reflectance and $B_{2}$ is red and MIR.

Snow and vegetation indices are based on similar simple linear band combinations. The soil-adjusted vegetation index (SAVI) was developed by Huete (1988) and Qi et al. (1994) to minimize soil influences on canopy spectra. This is made by incorporating a soil adjustment factor into the denominator of the normalized difference vegetation index (NDVI) equation (Huete et al. 1985, Huete 1989). Similarly, we attempt to modify the SI to take the soil influences into account. As far as we know from a literature review, this issue, which is frequently addressed for vegetation indices, is never investigated for snow indices. This is due to the fact that snow is predominantly studied in regions with extended snow cover. On our zone, very few fully covered pixels are present. The large majority of pixels are partially covered with snow. Consequently, the high spatial variability of the soil spectral signature has a strong impact on the snow index. In order to take these soil influences into account we correct the SI from the underlying soil spectral signature ' $\mathrm{SI}_{0}$ '. This correction is inversely proportional to the SCA (second right-end term in equation(3)). The modified snow index (MSI) is defined for each pixel by equation (3) where $\mathrm{SI}_{0}$ is the pixel's snow index corresponding to $\%$ snow cover and $\mathrm{SI}_{100}$ the snow index corresponding to a totally snow covered pixel.

$$
\mathrm{MSI}=\mathrm{SI}-\mathrm{SI}_{0} *\left(\frac{\mathrm{SI}_{100}-\mathrm{SI}}{\mathrm{SI}_{100}-\mathrm{SI}_{0}}\right)
$$

To set $\mathrm{SI}_{100}$ we analyse the maximum SI value of several snow covered regions: a value of $1000 \mathrm{dc}$ is kept. This value is unique and independent of the location. Figure 6 details the steps followed to determine the $\mathrm{SI}_{0}$ value of each pixel using seven snow-free SPOT-VGT images for several dates among several years. Each snow-free image is converted into an $\mathrm{SI}_{0}$ image and the mean $\mathrm{SI}_{0}$ image is then calculated. For each pixel, the $\mathrm{SI}_{0}$ is set to the average of its seven $\mathrm{SI}_{0}$ values. To calculate the MSI on each pixel of any SPOT-VGT image we thus have all necessary information: the $\mathrm{SI}_{0}$ pixel values (the mean $\mathrm{SI}_{0}$ pixel values), the $\mathrm{SI}_{100}$ and the $\mathrm{SI}$ pixel values for the image considered.

\subsection{Snow cover maps}

The index-to-area relation is established with respect to two types of method : the 'classical' and the 'improved' methods. The classical methods are based on two reference values corresponding to 0 and $100 \%$ snow cover. The improved method uses a larger number of points, thanks to the combination of high and low resolution satellite sensor data. 


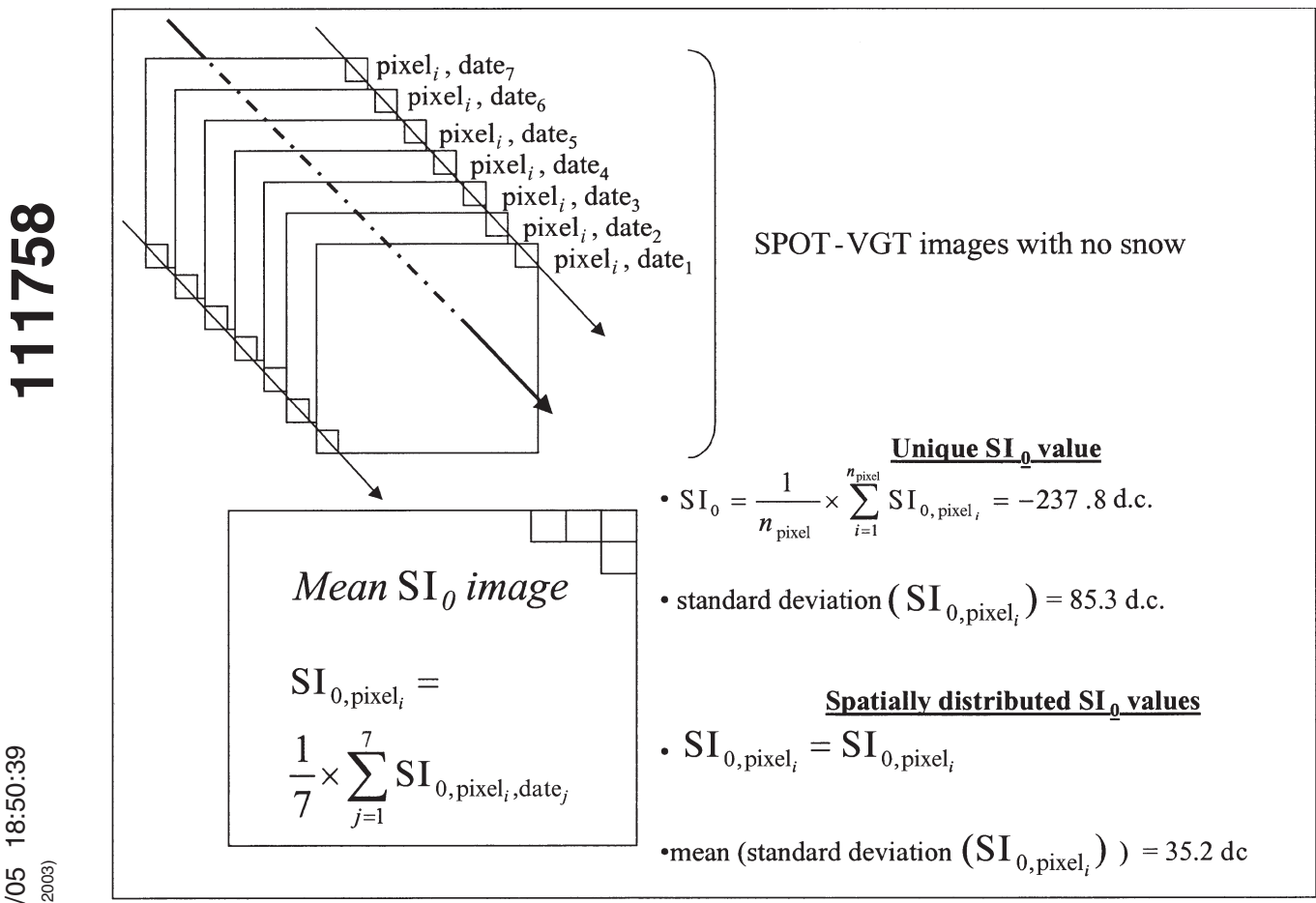

Figure 6. Unique and spatially distributed $\mathrm{SI}_{0}$. On seven snow-free images, temporal mean per pixel is calculated: spatially distributed $\mathrm{SI}_{0}$ values are obtained, their mean temporal standard deviation is $35.2 \mathrm{dc}$. Unique $\mathrm{SI}_{0}$ value is set as the mean of these spatially distributed values $(=-237.8 \mathrm{dc})$, its standard deviation is $85.3 \mathrm{dc}$.

3.3.1 The classical methods. Considering a unique reference value for the whole image is possible (Solberg and Andersen 1994), but authors mainly consider regional reference values (for instance, according to land cover type in Metsämäki et al. 2002 and Matikainen et al. 2002).

A number of issues are raised when setting these reference values since snow albedo is sensitive to many effects such as land cover, slope and aspect, snow grain size, aerosols contamination, shadow and atmospheric composition. The way these issues are tackled depends on the zone of interest and the authors.

- In forested lands, snow detection is complex and has been studied extensively (Koskinen et al. 1997, Hall et al. 1998, Matikainen et al. 2002, Metsämäki et al. 2002). The optical signature of a pixel being much higher on a snow-covered open area than on a snow-covered forest, it is necessary to distinguish land cover classes when estimating SCA. Because a low $(1 \mathrm{~km})$ spatial resolution pixel often contains several land cover types, linear mixture models are used to estimate the fractional area of a multiple cover-type within a pixel (Oleson et al. 1995). This requires previous knowledge of cover types reflectance (endmember spectra). These reflectances can be provided either by laboratory-derived spectral libraries or by selecting pixels which are known to be pure. The use of such libraries raises the problem of representativeness regarding the vegetation density and local characteristics. When using pure low spatial resolution pixels, issues of availability (is an image available on which the pure pixels are clear 
and 100\% snow covered?) and misclassification appear (Matikainen et al. 2002). Because the Atlas range is situated in a warmer region, snow is only present at very high elevations. At such elevations, vegetation is not able to survive and the underlying soil is bare. The issue to be addressed is then the spatial heterogeneity of the soil spectral signature. To solve this problem, two strategies are investigated in this paper: the use of local reference values (see below) and the development of a modified snow index (see above).

- All processes involving changes in snow reflectance, mostly decreasing albedo, can lead to snow cover underestimations (Warren and Wiscombe 1980): grain size and humidity increase, snow contamination with atmospheric aerosols (dust and soot). These processes are often neglected (Matikainen et al. 2002, Metsämäki et al. 2002) because their impact is secondary and they are difficult to consider. In what follows they are neglected.

- Image geometry (Sun zenith and azimuth angles, viewing zenith and azimuth angles) affects reflectance values. To correct these effects, bi-directional reflectance distribution functions are needed (Matikainen et al. 2002). Concerning the viewing angle we select images with low angles to minimize its impact, but variations in Sun angles remain.

Images used in this study are not corrected from atmospheric effects (as in Matikainen et al. 2002, Salomonson and Appel 2004). These effects are, however, minimized by selecting clear sky images with a low viewing angle, the shortest atmospheric width being thus crossed.

Two methods are investigated in the region of interest (see table 1), i.e. unique reference value for the whole image method (URVM) and local reference value method (LRVM).

\section{Unique reference value method}

To set a unique $\mathrm{SI}_{0}$ value (snow index corresponding to $0 \%$ snow cover) we calculate the spatial mean of the $\mathrm{SI}_{0}$ image (figure6) for the mountainous zone (values obtained: $\mathrm{SI}_{0}=-237.77 \mathrm{dc}$, spatial standard deviation $=85.3 \mathrm{dc}$ ). A linear relationship is assumed between points $(-237.77 \mathrm{dc}, 0 \%)$ and $(1000 \mathrm{dc}, 100 \%)$. A single relationship for the whole image is implemented.

\section{Local reference value method}

The $\mathrm{SI}_{100}$ value is the same as before $(1000 \mathrm{dc})$ but the $\mathrm{SI}_{0}$ value is set independently for each pixel. The mean $\mathrm{SI}_{0}$ image (figure 6) allocates to each pixel its own $\mathrm{SI}_{0}$ value. The mean temporal standard deviation of these spatially distributed $\mathrm{SI}_{0}$ is $35.2 \mathrm{dc}$. A linear relationship specific to each pixel is assumed between the points $\left(\mathrm{SI}_{0}, 0 \%\right)$ and $(1000 \mathrm{dc}, 100 \%)$. In doing so, we account for the spatial difference between soil signatures.

Note here that the index construction and the establishment of the index-to-area relationship are two independent aspects even if these make use of the same values $\left(\mathrm{SI}_{0}\right.$ and $\left.\mathrm{SI}_{100}\right)$.

3.3.2 The improved methods. From high spatial resolution data, we obtain reference SCA maps as described in \$3.1. For the calibration date, the reference SCA map is superimposed to the snow index map. For each low resolution snow index the corresponding SCA is thus known. This superimposition is made for the 
whole image, leading to several points from which to establish the relationship between index and area. In Salomonson and Appel (2004), scatter plots of normalized difference snow index from Moderate-resolution Imaging Spectroradiometer (MODIS) images versus fractional snow cover from Landsat TM are displayed for areas in Alaska, Siberia (Russia) and Labrador (Canada). Because these zones present a very important snow cover, a high number of points is available especially at both extreme snow fractions (0.0 and 1.0). For our zone, the snow index versus fractional snow cover scatter plot is displayed in figure 7(a) for the SI and in figure $7(b)$ for the MSI. It appears clearly that only a few points are available, which is directly due to the nature of the observed zone (a semi-arid mountain range). In addition a large scatter is observed, which is not surprising: scattering of snow signature is a well known and reported phenomenon (Warren and Wiscombe 1980). However, in our case, the scatter is particularly large since two effects are combined: snow signature variability and topographical aspects. In figure 7 the horizontal scatter is reduced for low SCA values, showing that the soil spectral signature contributes significantly to the noise contained in the SI. When it is taken into account (MSI) the index variations are more directly related to snow coverage. In spite of the large scatter, the plot seems to follow a sigmoid-shaped distribution, as in figure 4 in Salomonson and Appel (2004). A very high number of pixels being snow free or weakly snow covered, the scatter plot presents a very high density of points with low SCA values whereas only a few points present high SCA values.

From these plots a linear relationship can be extracted as in Fortin et al. (2000) or Salomonson and Appel (2004). In our case, it is clear that a linear regression relationship will lead to poor results because of the high density of low SCA values. A nonlinear relationship seems to be more suited. Among the different possible models, the most appropriate turns out to be a generalized logistic model, $y=\left(1-A \times \exp (-B x)^{C}\right)$ with $A, B$ and $C$ being calibration parameters. To set the calibration parameters, we choose a nonlinear median quintile regression (Koenker 2000) which assumes no specific error distribution compared to rms error minimization. Figure 7(a) displays the results (see equation(4)) obtained when applying this model for the SI and figure $7(b)$ the results obtained with the MSI (see equation (5)). The relations established on the calibration date are then used for the validation date.

$$
\begin{aligned}
& y=\left(1-1.76 * \exp ^{-0.52 *\left(\frac{\mathrm{SI}}{100}+5\right)}\right)^{20} \\
& y=\left(1-0.49 * \exp ^{-0.69 *\left(\frac{\mathrm{MSI}}{100}+1\right)}\right)^{20}
\end{aligned}
$$

\subsection{Validation}

Different methods can be used to compare images (Davis et al. 1995, Luce et al. 1998, Grayson et al. 2002). Point-by-point methods include the coefficient of determination and coefficient of efficiency calculated on the simulated versus reference plot, the mean error and the error variance. Global methods include visual analysis of maps (Grayson et al. 2002) and the confusion matrix and related kappa coefficient (Congalton and Green 1999). 
A. Chaponnière et al.

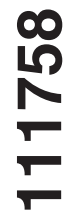

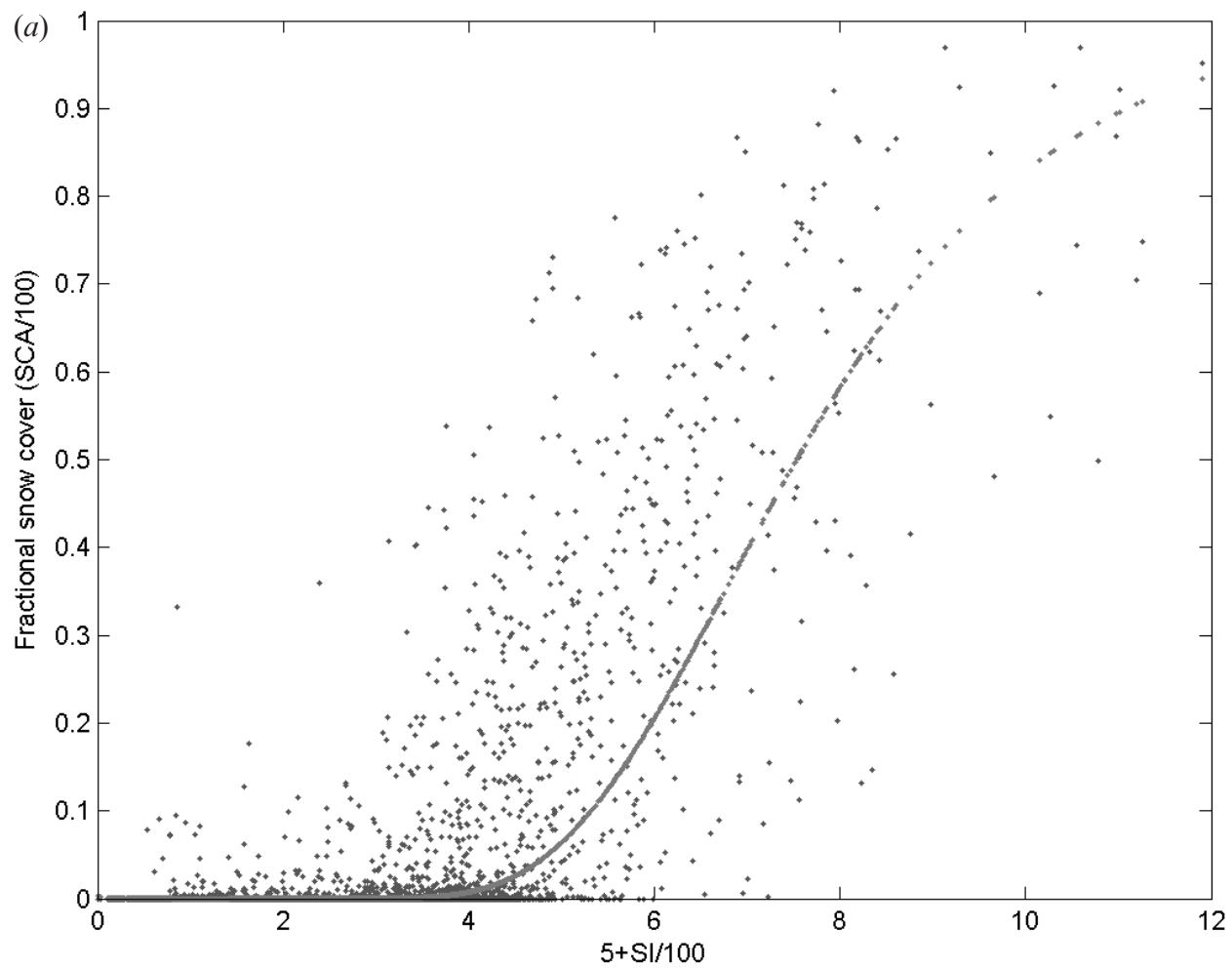

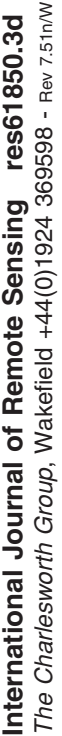

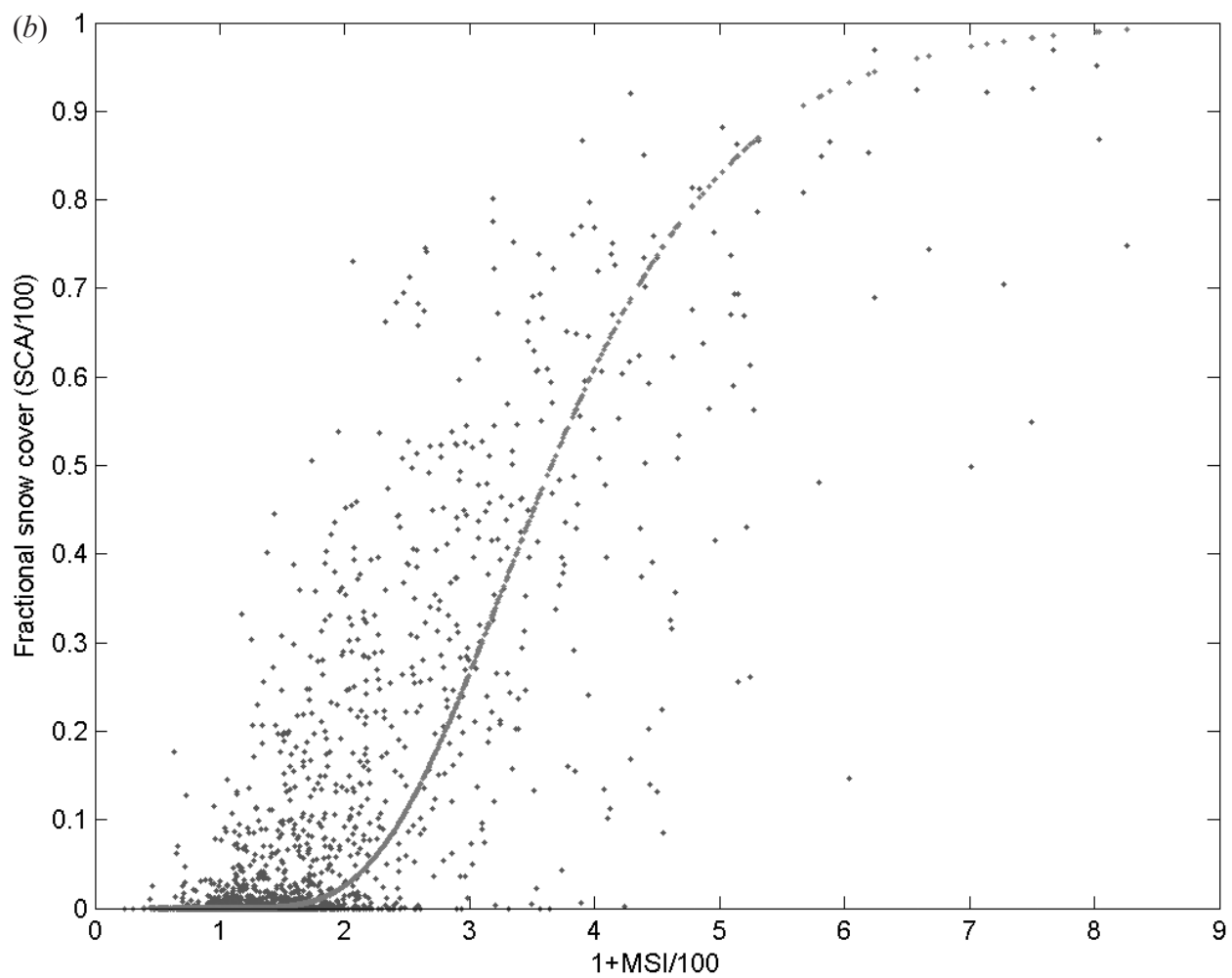


Table 2. Scatter plot parameter (correlation coefficient, rms error, kappa coefficient) for the four investigated methods for the calibration date ( 8 February 2002, left) and validation date (3 February 2000, right). The method in bold characters is the one we kept for temporal snow profiles illustration.

\begin{tabular}{lcccccccc}
\hline & \multicolumn{2}{c}{ Correlation coefficient } & & \multicolumn{2}{c}{ rmse } & & \multicolumn{2}{c}{ Kappa coefficient } \\
\cline { 2 - 3 } & Calibration & Validation & & Calibration & Validation & & Calibration & Validation \\
\hline URVM & 0.65 & 0.75 & & 6.95 & 6.38 & & 0.14 & 0.21 \\
LRVM & 0.75 & 0.77 & & 5.70 & 6.25 & & 0.34 & 0.38 \\
HR-LR_SI & 0.75 & 0.81 & & 5.60 & 5.49 & & 0.45 & 0.43 \\
HR-LR_MSI & $\mathbf{0 . 8 2}$ & $\mathbf{0 . 7 9}$ & & $\mathbf{4 . 8 9}$ & $\mathbf{5 . 9 9}$ & & $\mathbf{0 . 5 1}$ & $\mathbf{0 . 4 5}$ \\
\hline
\end{tabular}

Here, we consider two types of evaluation criteria for each method:

1. point-by-point criteria using correlation coefficient and rms error (rmse) between estimated and reference SCA maps; and

2. kappa coefficient between estimated and reference SCA maps are calculated as global criteria. We calculate the confusion matrix and kappa coefficient based on six classes of SCA values $\left(0-5 \mathrm{ha} \mathrm{km}^{-2}, 5-20,20-40,40-60,60-80\right.$, $80-100)$.

\section{Results and discussion}

\subsection{Classical methods: unique versus local reference value methods (URVM and LRVM)}

In table 2, the correlation coefficient, rmse and kappa coefficient obtained on the validation date when implementing classical methods are mentioned. The related SCA maps are presented in figure $8(a)$ and $(b)$. Taking the $\mathrm{SI}_{0}$ spatial variability (LRVM) into account gives better results than considering a unique $\mathrm{SI}_{0}$ value (URVM) for each parameter (table 2), particularly for the kappa coefficient, which is the most sensible to spatial restitution quality. On the SCA maps (figure 8(a) and (b)) very high amounts of sparse snow patches are detected where no snow is actually present (compare figure $8(a),(b)$ and figure $5(b)$ ). When the LRVM is implemented (figure $8(b)$ ), these patches are highly reduced but do not disappear completely. Whereas snow cover extent is overestimated, high SCA values are underestimated. On the three main patches of high SCA values detected on the reference SCA map-SCA between $80-100 \%$, see figure 5(b), SCA values between $55-75 \%$ are estimated via the reference value methods (figure $8(a)$ and $(b)$ ). These results underline the importance of the soil spectral signature effect when dealing with snow detection at low resolution. When considering reference values, the linear relationships overestimate SCA for low SCA values and underestimate it for high SCA values.

Figure 7. Superimposition of snow index (calculated on low resolution image) to snow surface (derived from degraded high resolution snow classification) for establishing the indexto-area relationship. A nonlinear quintile regression (median quintile) is fitted on the snow indices SI $(a)$ and MSI $(b)$. 
(a)

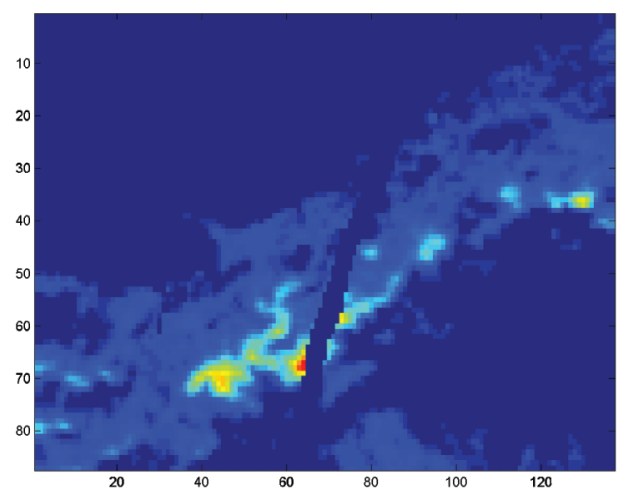

(c)

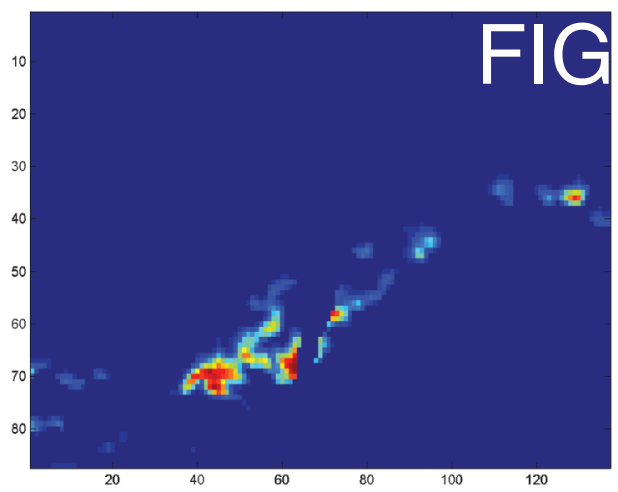

(b)

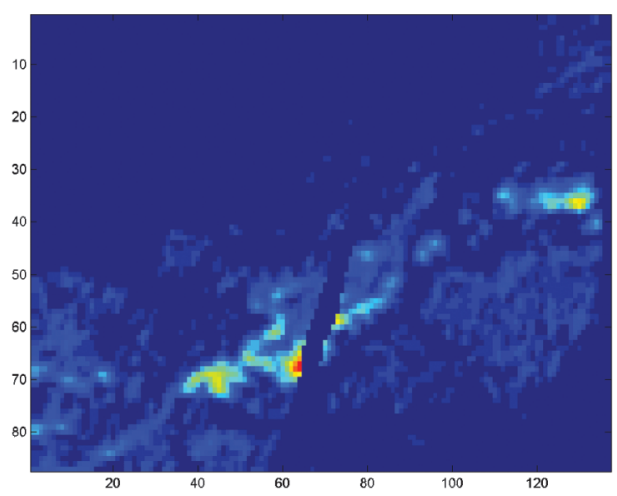

(1)

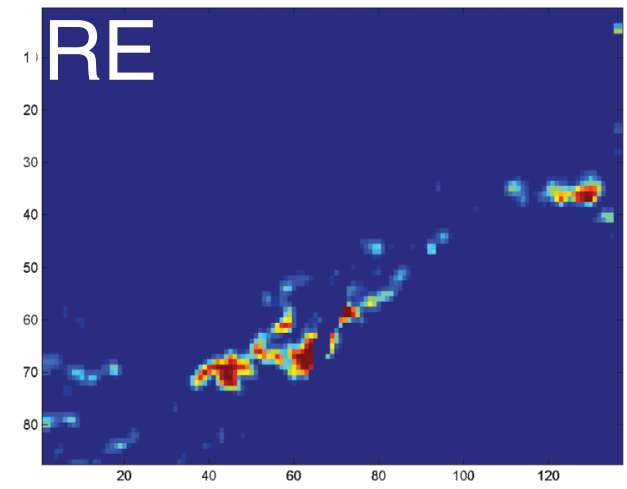

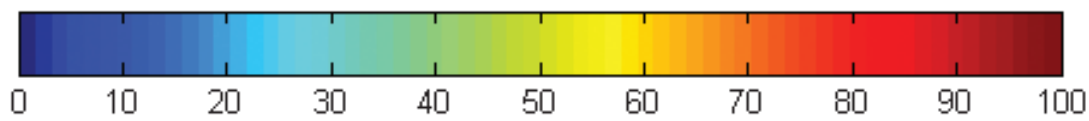

Figure 8. SCA maps on the validation date, obtained following the different methods: $\operatorname{URVM}(a), \operatorname{LRVM}(b)$, HR-LR_SI $(c)$, and HR-LR_MSI $(d)$.

\subsection{Improved method with SI and MSI}

The analysis of improved methods is performed from table 2 and figure $8(c)$ and $(d)$ against the reference SCA maps (see figure 5(b)). When compared to reference value methods, the improvement is statistically described by the criteria presented in table $2\left(r^{2}\right.$, rmse, kappa coefficient). When compared to the reference map computed for the validation date, detection of snow appears to be much more spatially accurate than for reference value methods. Less sparse patches are detected and high SCA values are obtained at the correct locations (compare figure 5(b) and figure 8). Figure $8(c)$ and $(d)$ display the SCA maps using SI and MSI, respectively. The comparison between snow indices points out that the MSI leads to a better estimation than SI. When using MSI, the SCA map is closer to the reference one (compare figure $8(d)$ and figure $5(b)$ ) and the kappa coefficient is higher (table 2). For the calibration date, the improvement is significant as shown for all the statistical criteria we use. For the validation date, MSI does not give better results for rmse and correlation coefficient. This may indicate a higher sensitivity of the improved method based on MSI to calibration. Despite this sensitivity, we consider 
this method as the best one since the kappa coefficient is the highest and spatial patterns are well reproduced.

The selected method is applied subsequently to a one-year time series of SPOTVGT data.

\subsection{Comparison between classical and improved methods}

Figure 9, displaying the $\mathrm{SI}_{0}$ values spatial distribution (figure $9(a)$ ) and its histogram (figure $9(b)$ ), helps to understand the differences between the URVM and LRVM results.

The URVM considers a unique relation linking the snow index to the snow area. This linear relation joins points $(-237.77 \mathrm{dc}, 0 \%)$ and $(1000 \mathrm{dc}, 100 \%)$. On the other hand, the LRVM considers a index-to-area relation per pixel, each relation linking points $\left(\mathrm{SI}_{0}, 0 \%\right)$ and $(1000 \mathrm{dc}, 100 \%)$. The LRVM and URVM regression lines differ only by their slope. Consequently, for pixels with an $\mathrm{SI}_{0}$ lower than the mean $\mathrm{SI}_{0}$, the snow cover is underestimated if one sets a unique $\mathrm{SI}_{0}$ value. For pixels with an $\mathrm{SI}_{0}$ greater than the mean, snow cover is overestimated. This is illustrated in figure $8(a)$, (b) and figure $9(a)$, (b). For zones with an $\mathrm{SI}_{0}$ around $-350 \mathrm{dc}$, the URVM detects no snow whereas the LRVM does. Zones presenting high values of $\mathrm{SI}_{0}$ (values higher than the $\mathrm{SI}_{0}$ mean) are detected as snow covered with the URVM and snow free with the LRVM.

Zones with a high snow cover present high $\mathrm{SI}_{0}$ values; this is probably due to their high elevation and thus absence of shadow effect, which lowers the $\mathrm{SI}_{0}$ values. The regression of the URVM presents a lower slope than the LRVM regression line for a pixel presenting a high $\mathrm{SI}_{0}$ value. Consequently, for high snow coverage the URVM underestimates snow cover in these zones compared to the LRVM.

Concerning the improved methods, the main limitation comes from the important scatter of each curve. Although reduced when using MSI instead of SI, the scatter is still important and is mainly due to differences in a pixel's insolation. Selecting a subset of the image could reduce this scatter but we choose to plot all the pixels contained in the image. This ensures a higher regional representativeness of the method. The relation is established and is valid for the part of the Atlas we selected. It might not be valid for the whole image if we choose a subset. Consequently, it might not be valid for a region of the Atlas which is not covered by our image. The application presented below concerns a zone within this larger area.

To reduce the scatter the use of atmospherically corrected images can lead to better results. However, the most efficient method is the use of higher spatial resolution images like MODIS. The capabilities of these data for this methodology will be analysed in the near future.

\section{Temporal snow profiles}

We selected the method in the previous section that gives the best spatial restitution of snow cover in terms of snow surface and snow location. It is the one using the MSI and the index-to-area relation deduced from high and low resolution combination. We apply this method to a time series of SPOT-VGT images as a test for further operational use. The SPOT-VGT images of winter 1998-99 appear cloud free on the quick-look images. Yet, a cloud mask based on a threshold of the 


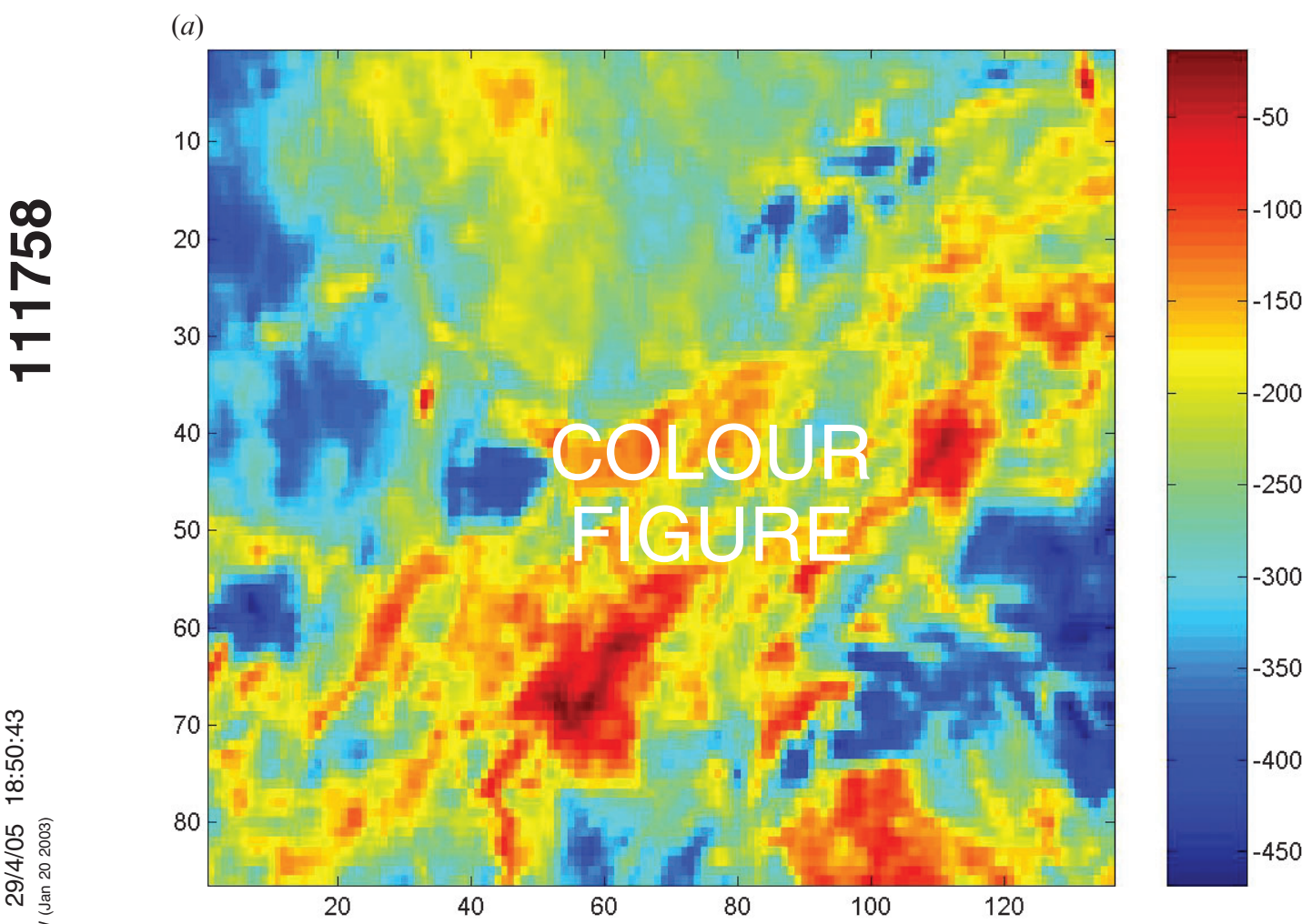

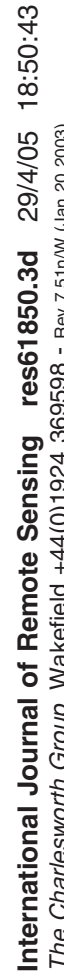

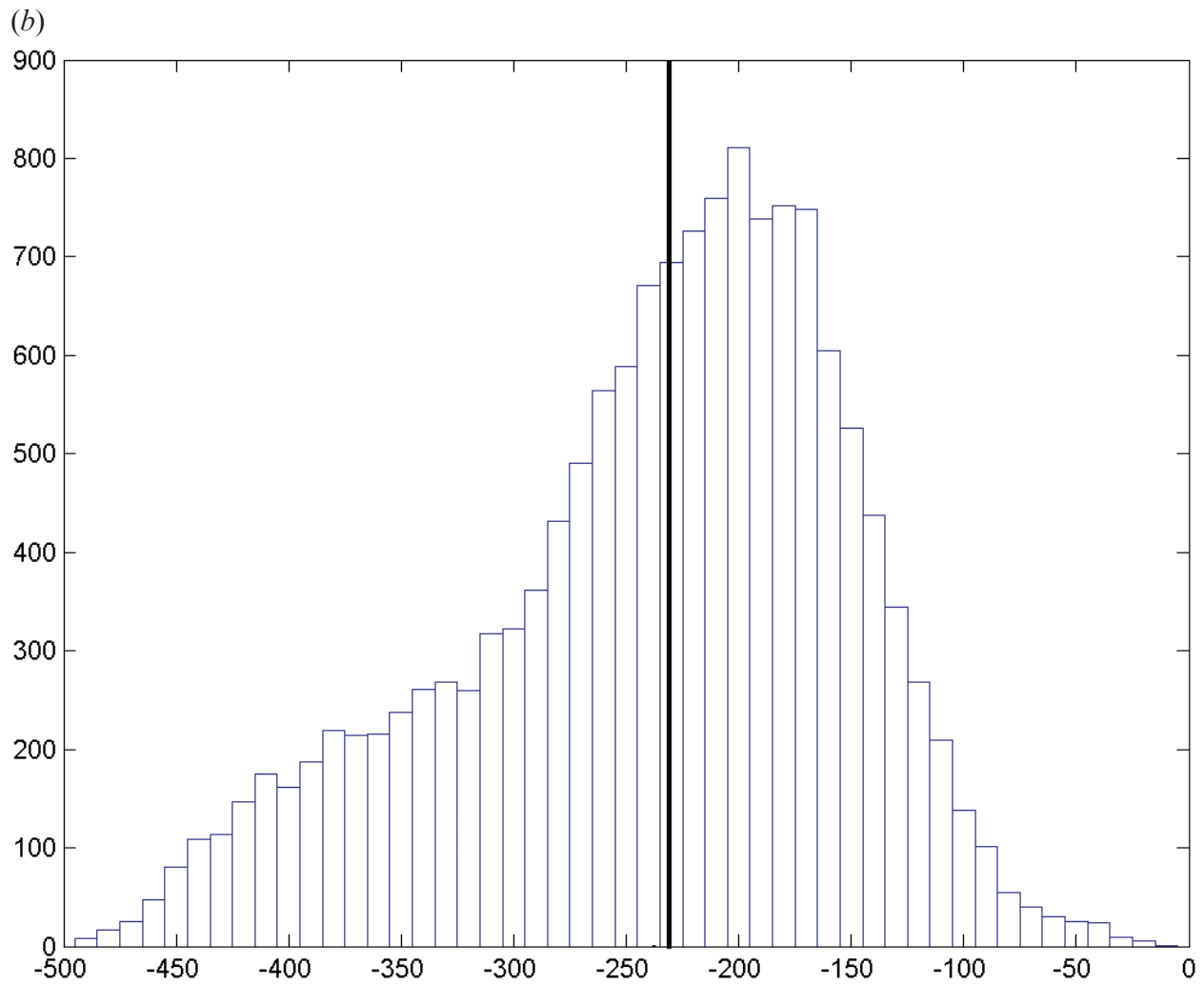




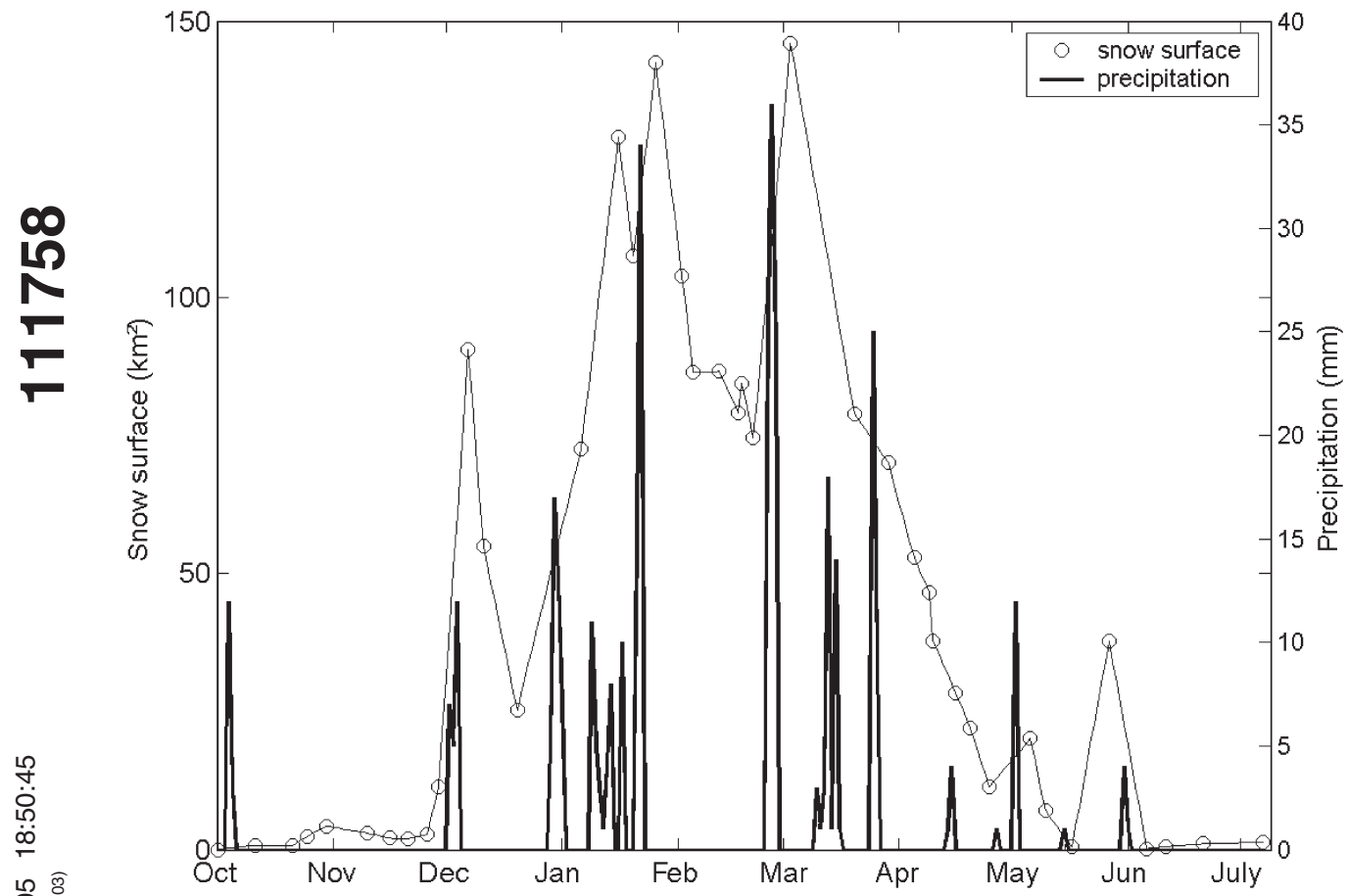

Figure 10. Precipitation in $\mathrm{mm}$ at the Rehraya watershed's outlet and snow surface over the watershed in $\mathrm{km}^{2}$ between October 1998 and July 1999.

MIR reflectance (band 4) is applied to ensure the absence of smaller clouds undetected on the quick-looks.

Results are illustrated at the watershed scale (Rehraya watershed, $228 \mathrm{~km}^{2}$ ). Snow surface over the watershed is compared with precipitation and river stage measurements at the watershed's outlet.

In figure 10, snow surfaces in $\mathrm{km}^{2}$ of the Rehraya watershed are plotted against precipitation measured at the watershed's outlet. The outlet is located at $1000 \mathrm{~m}$ above sea level. At this elevation in the Atlas, snowfall almost never occurs. From October to December 1998 and from June to July 1999, no snow was detected on the watershed. Precipitation events observed at the outlet might occur on the whole watershed but in liquid form. Between December and May, we notice a good correlation between rainfall events and the watershed snow cover. It indicates that during winter, precipitation at the outlet seems to be representative of the precipitation occurring on the watershed, at least for 1998-99. This is an interesting point for hydrological modelling. It means that the use of a temperature gradient with elevation can be sufficient to represent the solid and liquid precipitation events on the watershed.

In figure 11 the watershed SCA values in $\mathrm{km}^{2}$ are plotted against the runoff data in $\mathrm{m}^{3} \mathrm{~s}^{-1}$. Before February, although high amounts of snow were present on the watershed, the runoff was very low. Snowmelt seems to begin in February, inducing an increase of runoff. The snow depletion curve (decrease of SCA values) coincides

Figure 9. $\mathrm{SI}_{0}$ values: the spatial distribution of $\mathrm{SI}_{0}$ in the region of interest $(a)$ and the corresponding histogram $(b)$ with the mean $\mathrm{SI}_{0}$ value represented by the thick black line. 


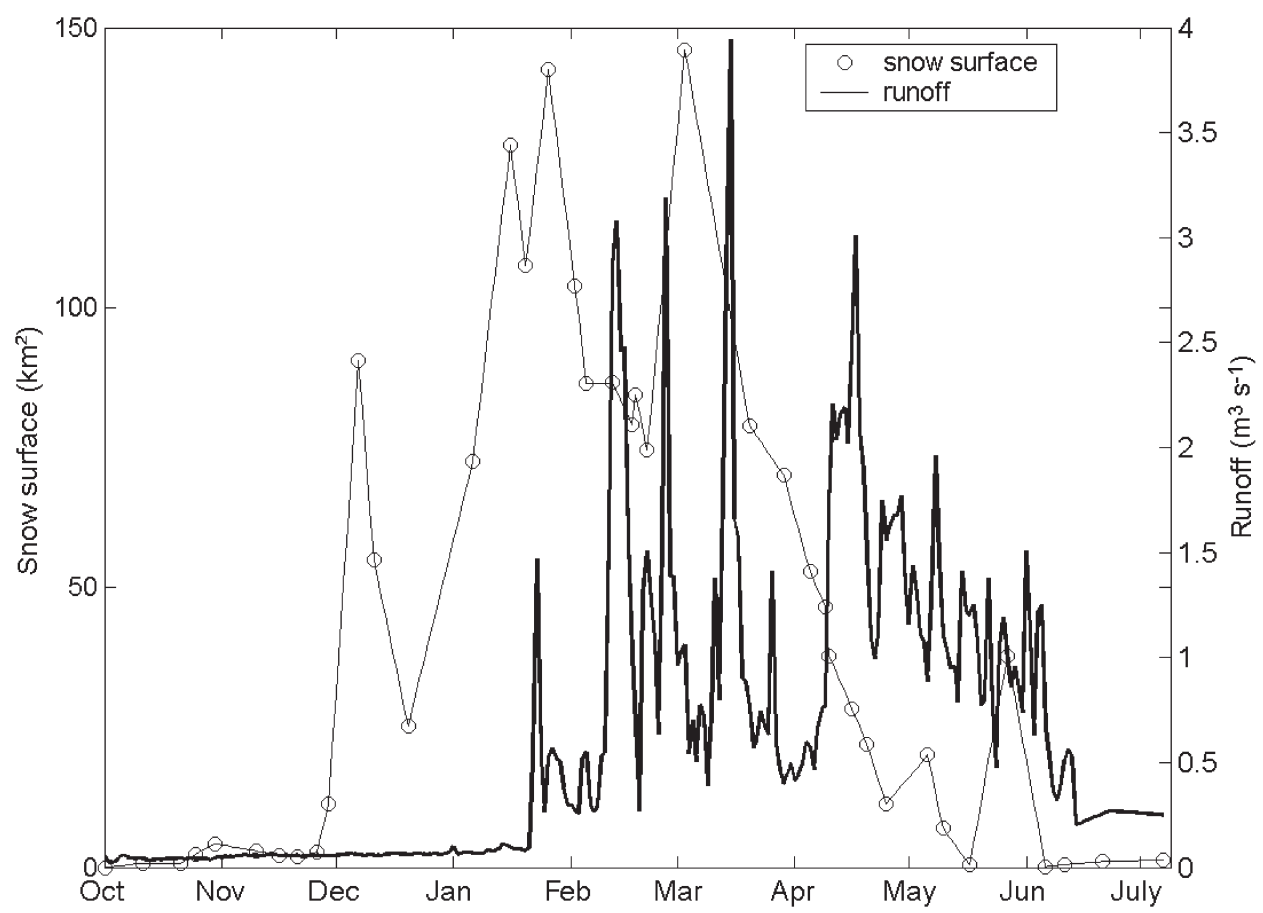

Figure 11. Runoff measures in $\mathrm{m}^{3} \mathrm{~s}^{-1}$ at the Rehraya watershed's outlet and snow surface over the watershed in $\mathrm{km}^{2}$ between October 1998 and July 1999.

with an increase in runoff. The lag factor induced by snowmelt causes a sustained runoff at the end of spring and the beginning of summer although no precipitation occurs at that time.

However, we can note that given the watershed morphology (steep slopes, bare soils, superficial bedrock), a quicker response to snowmelt is expected than what the runoff data actually show. It seems that some processes are responsible for an additional delay. The important snow cover fluctuations in January and February do not result in increased runoff. Also, high discharge is observed several months after the main snow depletion. The delayed water release could be due to infiltration in the bedrock's pervious zones or soil water storage fluctuations. The assumption of deep infiltration is supported by the existence of springs and wells in the watershed. We undertook some geochemical analyses to test this assumption.

\section{Conclusion}

In Morocco high concern exists on water resources identification and quantification. In the Tensift watershed, the high Atlas range represents the most important water supply of the region through liquid but also solid precipitation. Improved knowledge about the snow-water storage is of prime importance since the latter is not currently monitored. In this study a method based on satellite imagery is developed to estimate snow cover over the high Atlas mountain range.

The results obtained with the reference value methods show that in mountainous terrain, the snow surface cannot be accurately derived from low resolution data. We nevertheless notice a significant improvement by using local reference values. This is 
due to the strong impact of soil spectral properties on the snow index 'SI'. A modified snow index 'MSI' corrected for soil influence is therefore proposed.

A method is also developed by fitting the index-to-area relation on a large number of points. These points are obtained by superimposing high and low spatial resolution data. The new method is applied to both indices (SI and MSI). When applied to MSI the method leads to a significant improvement of the snow cover area maps in terms of snow location and snow surface estimations. This optimal method is proposed for low resolution data. Indeed, satellite monitoring of snow cover requires imagery with high temporal frequency. So far this temporal frequency is provided only by low spatial resolution instruments such as SPOT VEGETATION. A sensor combining high spatial and temporal resolution would improve further the results, particularly in high mountainous zones such as the Atlas range.

The comparison of temporal snow surface profiles obtained by this method for 1998-99 with downstream precipitation and runoff shows a global consistency. The approach developed demonstrates satisfactory reliability and will be used for future hydrological modelling validation and hydrological data assimilation.

\section{Acknowledgments}

This investigation is conducted within the frame of the SUDMED project. The authors would like to thank all the project participants especially the Agence de Bassin Hydraulique du Haouz-Tensift for providing the ground data. Research has been partially supported through the IRRIMED project funded by the European Commission (INCO-MED programme). Many thanks to Dr A. Chehbouni (CESBIO) for supervising this work and helping in the writing of the paper. The authors would like to thank Dr R. Faivre (INRA) and J. F. Reulet (CNES) for helping in some data processing. Valuable comments by two anonymous reviewers helped improve the manuscript.

\section{References}

Akyürek, Z. and Sorman, A.Ü., 2002, Monitoring snow-covered areas using NOAAAVHRR data in the eastern part of Turkey. Hydrological Sciences Journal des Sciences Hydrologiques, 47(2), pp. 243-252.

BARAL, D.J. and GUPTAL, R.P., 1997, Integration of satellite sensor data with DEM for the study of snow cover distribution and depletion pattern. International Journal of Remote Sensing, 18, pp. 3889-3894.

Blöschl, G., 1999, Scaling issues in snow hydrology. Hydrol. Process, 13, pp. 21492175.

Chaponnière, A., Boulet, G., Maisongrande, P. and Chehbouni, A., 2003, Simulation of 6 the hydrological regime of a small semi-arid mountainous watershed in Morocco. EGS-AGU-EUG General Assembly, 6-11 April 2003, Nice, France.

Congalton, R.G. and Green, K., 1999, Assessing the Accuracy of Remotely Sensed Data: Principles and Practices (Boca Raton: Lewis).

Cruette, J., 1976, Pluviométrie du bassin du Tensift. Royaume du Maroc, Ministère des Travaux Publics et Communications, Direction de l'Hydraulique, Division des Ressources en Eau. ORSTOM, France.

Davis, E.R., McKenZie, J.C. and Jordan, R., 1995, Distributed snow process modeling: an image processing approach. Hydrol. Process, 9, pp. 865-875.

de Solan, B., Chaponnière, A., Maisongrande, P., Duchemin, B., Hanich, L. and Chehbouni, G., 2002, Cartographie de l'enneigement par télédétection à partir d'images SPOT VEGETATION et Landsat TM: application à l'Atlas marocain. 
Séminaire international 'Hydrologie nivale en méditerranée', Décembre 2002, Beyrouth, Lebanon. p 2.

Dozier, J., 1989, Spectral signature of alpine snow cover from the Landsat Thematic Mapper. Remote Sensing of Environment, 28, pp. 9-22.

Fortin, F., Bernier, M., Battay, A.E., Gauthier, Y. and Turcotte, R., 2000, Estimation of surface variables at the sub-pixel level for use as input to climate and hydrological models. Proceedings of VEGETATION 2000 Symposium, 3-6 April 2000, Lake Maggiore, Italy.

Grayson, R.B., Blöschl, G., Western, A.W. and McMahon, T.A., 2002, Advances in the use of observed spatial patterns of catchment hydrological response. Advances in Water Resources, 25, pp. 1313-1334.

Hall, D.K., Riggs, G.A. and Salomonson, V.V., 1995, Development of methods for mapping global snow cover using Moderate Resolution Imaging Spectroradiometer data. Remote Sensing of Environment, 54, pp. 127-140.

Hall, D.K., Foster, J.L., Verbyla, D.L., Klein, A.G. and Benson, C.S., 1998, Assessment of snow-cover mapping accuracy in a variety of vegetation-cover densities in central Alaska. Remote Sensing of Environment, 66, pp. 129-137.

Hallikainen, M.T. and Jolma, P., 1992, Comparison of algorithms for retrieval of snow water equivalent from Nimbus-7 SMMR data in Finland. IEEE Transactions on Geoscience and Remote Sensing, 30, pp. 124-131.

Hanich, L., De Solan, B., Duchemin, B., Maisongrande, P., Chaponnière, A., Boulet, G. and Chehbouni, G., 2003, Snow cover mapping using SPOT VEGETATION with high resolution data: application in the Moroccan Atlas mountains. Proceedings of IEEE International Geoscience and Remote Sensing Symposium (IGARSS), 21-25 July 2003, Toulouse, France.

Huete, A.R., 1988, A soil-adjusted vegetation index (SAVI). Remote Sensing of Environment, 25, pp. 53-70.

HuEte, A.R., 1989, Soil influences in remotely sensed vegetation-canopy spectra. In Theory and Applications of Optical Remote Sensing, G. Asrar (Ed), pp. 107-141.

Huete, A.R., JACKSON, R.D. and Post, D.F., 1985, Spectral response of a plant canopy with different soil backgrounds. Remote Sensing of Environment, 17, pp. 37-53.

Koenker, R., 2000, Quintile regression. In International Encyclopedia of the Social 12 Sciences, S. Fienberg and J. Kadan (Eds).

Koskinen, J.T., Pulliainen, J.T. and Hallikainen, M.T., 1997, The use of ERS-1 SAR data in snow melt monitoring. IEEE Transactions on Geoscience and Remote Sensing, 35, pp. 601-610.

Lissens, G., Kempeneers, P. and Fierens, F., 2000, Development of a cloud, snow and 13 cloud shadow mask for VEGETATION imagery. Proceedings of VEGETATION 2000 Symposium, 3-6 April 2000, Lake Maggiore, Italy.

Luce, C.H., Tarboton, D.G. and Cooley, K.R., 1998, The influence of the spatial 14 distribution of snow on basin-averaged snowmelt. Hydrol. Process, 12, pp. 1671-1683.

Maisongrande, P., Duchemin, B. and Dedieu, G., 2004, VeGeTATION/SPOT: an operational mission for the Earth monitoring; presentation of new standard products. International Journal of Remote Sensing, 25, pp. 9-14.

Maselli, F., Amparo Gilabert, M. and Conese, C., 1998, Integration of high and low resolution NDVI data for monitoring vegetation in Mediterranean environments. Remote Sensing of Environment, 63, pp. 208-218.

Matikainen, L., Kuittinen, R. and Vepsäläinen, J., 2002, Estimating drainage area-based snow-cover percentages from NOAA AVHRR images. International Journal of Remote Sensing, 23, pp. 2971-2988.

Metsämäki, S., Vepsäläien, J., Pulliainen, J. and Sucksdorff, Y., 2002, Improved linear interpolation method for the estimation of snow-covered area from optical data. Remote Sensing of Environment, 82, pp. 64-78. 
Oleson, K.W., Sarlin, S., Garrison, J., Smith, S., Privette, J.L. and Emery, W.J., 1995, Unmixing multiple land-cover type reflectances from coarse spatial resolution satellite data. Remote Sensing of Environment, 54, pp. 98-112.

ORSTOM, 1976, Hydrologie du bassin du Tensift. Royaume du Maroc, Ministère des travaux publics et communications, Direction de l'Hydraulique, Division des Ressources en Eau.

Qi, J., Chehbouni, A., Huete, A.R., Kerr, Y. and Sorooshian, S., 1994, A modified Soil Adjusted Vegetation Index. Remote Sensing of Environment, 48, pp. 119-126.

RANGO, A. and ItTEN, K.I., 1976, Satellite potentials in snowcover monitoring and runoff 15 prediction. Nordic Hydrol, 7, pp. 209-230.

Robinson, D.A., 1993, Hemispheric snow cover from satellites. Ann. Glaciol, 17, pp. 367-371. 16

Robinson, D.A., Dewey, K.F. and Heim, R.R., 1993, Global snow cover monitoring: an update. Bulletin of the American Meteorological Society, 74, pp. 1689-1696.

RosenthaL, W., 1993, Mapping montane snow cover at subpixel resolution from the Landsat Thematic Mapper. MA thesis, University of California, Santa Barbara, USA.

Rosenthal, W. and Dozier, J., 1996, Automated mapping of montane snow cover at 17 subpixel resolution from the Landsat Thematic Mapper. Water Resour. Res, 32(1), pp. $115-130$.

SAlomonson, V.V. and ApPel, I., 2004, Estimating fractional snow cover from MODIS using the normalized difference snow index. Remote Sensing of Environment, 89, pp. 351-360.

Simpson, J.J., Stitt, J.R. and Sienko, M., 1998, Improved estimates of the areal extent of snow cover from AVHRR data. Journal of Hydrology, 204, pp. 1-23.

Solberg, R. and Andersen, T., 1994, An automatic system for operational snow-cover monitoring in the Norwegian mountain regions. International Geoscience and Remote Sensing Symposium, IGARSS'94, Pasadena, California (Piscataway, NJ: IEEE), pp. 2084-2086.

Warren, S.G. and Wiscombe, W.J., 1980, A model for the spectral albedo of snow. II: Snow containing atmospheric aerosols. Journal of the Atmospheric Sciences, 37, pp. 2734-2745. 


\section{Authors Queries}

Journal: International Journal of Remote Sensing

Paper: 111758

Title: A combined high and low spatial resolution approach for mapping snow covered area in the Atlas mountains

\section{Dear Author}

During the preparation of your manuscript for publication, the questions listed below have arisen. Please attend to these matters and return this form with your proof. Many thanks for your assistance

\begin{tabular}{|c|c|c|}
\hline $\begin{array}{l}\text { Query } \\
\text { Reference }\end{array}$ & Query & Remarks \\
\hline 1 & Guptal - should this be Gupta? & \\
\hline 2 & $\begin{array}{l}\text { 'Matikainen 2002' changed to } \\
\text { 'Matikainen et al. 2002' - cor- } \\
\text { rect as edited? }\end{array}$ & \\
\hline 3 & $\begin{array}{l}\text { Akyürek and Sorman } 2002-\text { is } \\
\text { this the correct journal title - } \\
\text { English? French? }\end{array}$ & \\
\hline 4 & Guptal - should this be Gupta? & \\
\hline 5 & $\begin{array}{l}\text { Blöschl } 1999 \text { - references } \\
\text { require full journal title. }\end{array}$ & \\
\hline 6 & $\begin{array}{l}\text { Chaponnière et al. } 2003- \\
\text { place of publication? publisher? } \\
\text { pages? }\end{array}$ & \\
\hline 7 & $\begin{array}{l}\text { Davis et al. } 1995 \text { - references } \\
\text { require full journal title. }\end{array}$ & \\
\hline 8 & $\begin{array}{l}\text { de Solan et al. } 2002 \text { - place of } \\
\text { publication? publisher? page } \\
\text { range? }\end{array}$ & \\
\hline 9 & $\begin{array}{l}\text { Fortin et al. } 2000 \text { - place of } \\
\text { publication? publisher? pages? }\end{array}$ & \\
\hline 10 & $\begin{array}{l}\text { Hanich et al. } 2003 \text { - place of } \\
\text { publication? publisher? pages? }\end{array}$ & \\
\hline
\end{tabular}




\begin{tabular}{|c|c|}
\hline 11 & $\begin{array}{l}\text { Huete } 1989 \text { - place of publica- } \\
\text { tion? publisher? }\end{array}$ \\
\hline 12 & $\begin{array}{l}\text { Koenker } 2000 \text { - place of pub- } \\
\text { lication? publisher? pages? }\end{array}$ \\
\hline 13 & $\begin{array}{l}\text { Lissens et al. } 2000 \text { - place of } \\
\text { publication? publisher? pages? }\end{array}$ \\
\hline 14 & $\begin{array}{l}\text { Luce et al. } 1998 \text { - references } \\
\text { require full journal title. }\end{array}$ \\
\hline 15 & $\begin{array}{l}\text { Rango and Itten } 1976 \text { - refer- } \\
\text { ences require full journal title. }\end{array}$ \\
\hline 16 & $\begin{array}{l}\text { Robinson } 1993 \text { - references } \\
\text { require full journal title. }\end{array}$ \\
\hline 17 & $\begin{array}{l}\text { Rosenthal and Dozier } 1996- \\
\text { references require full journal } \\
\text { title. }\end{array}$ \\
\hline
\end{tabular}

